\title{
Spontaneous Formation of Vesicular Assembly by Trimesic Acid Based Triple Tailed Amphiphile
}

\author{
Soumik Dinda, Moumita Ghosh and Prasanta Kumar Das* \\ Department of Biological Chemistry, Indian Association for the Cultivation of Science \\ Jadavpur, Kolkata - 700 032, India
}

\section{Supporting Information}

*To whom correspondence should be addressed. E-mail: bcpkd@iacs.res.in 


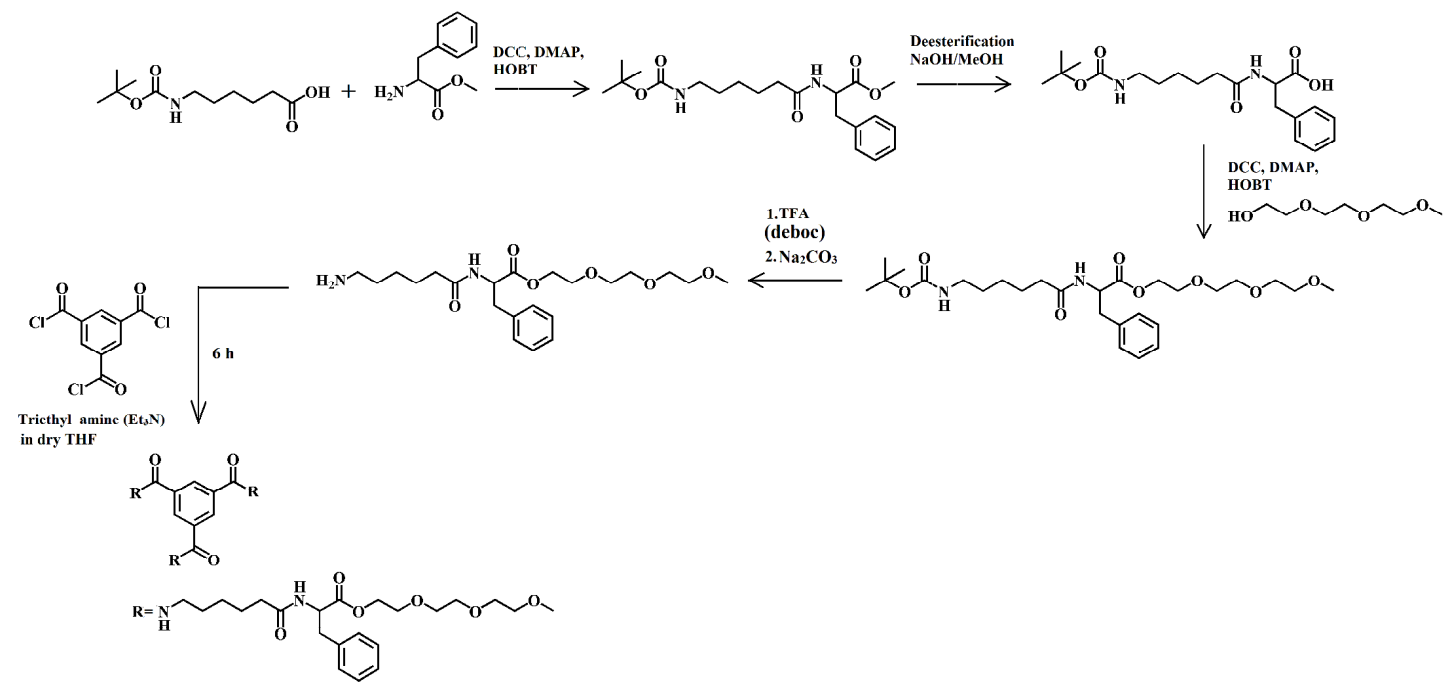

Scheme S1. Synthetic scheme for TMA-1. 


\section{Characterization of TMA-1.}

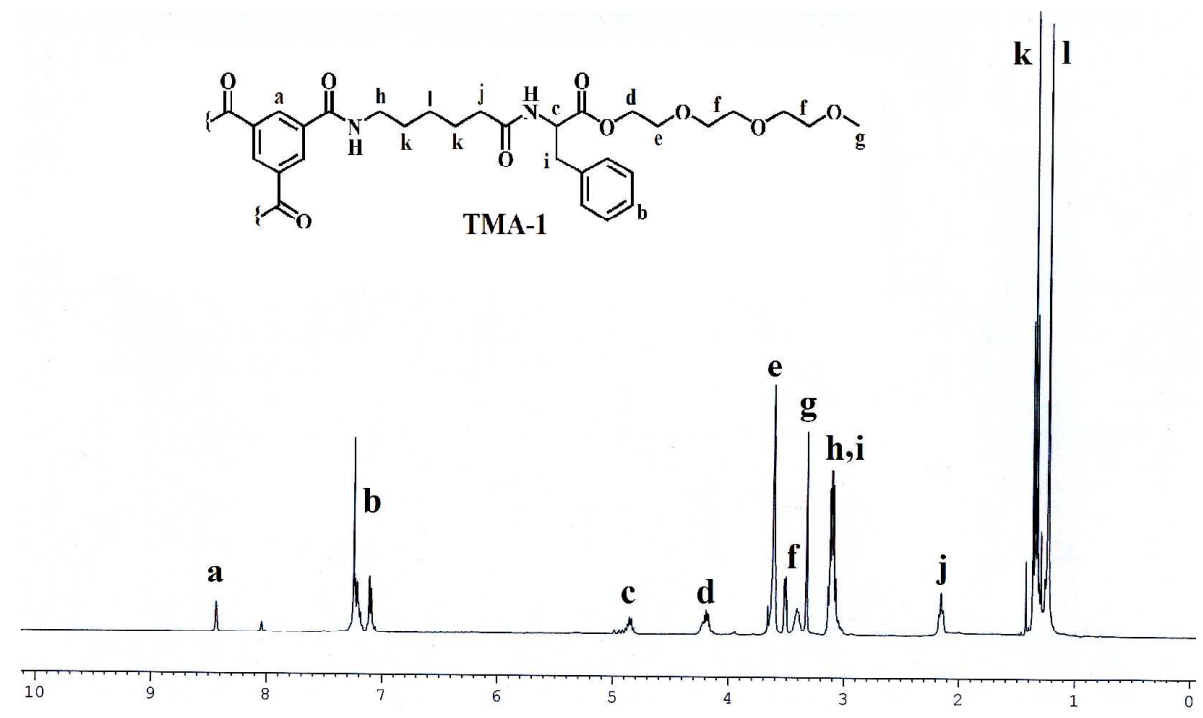

Figure S1. ${ }^{1} \mathrm{H}$ NMR spectra of TMA-1.

${ }^{1} \mathrm{H}$ NMR of TMA-1 (500 MHz, $\left.\mathrm{CDCl}_{3}, 25^{\circ} \mathrm{C}\right) . \delta=1.17-1.28\left(\mathrm{~m}, 6 \mathrm{H},-\mathrm{CH}_{2}-\mathrm{CH}_{2}-\mathrm{CH}_{2}-\right)$, 1.291.40 (m, 12H, - $\underline{\mathrm{CH}}_{2}-\mathrm{CH}_{2}-\underline{\mathrm{C}}_{2}-$ ), 2.14-2.17 (t, 6H, $\left.\underline{\mathrm{C}}_{2}-(\mathrm{CO})-\right), 3.02-3.14$ (m, $12 \mathrm{H}, \mathrm{Ph}-\underline{\mathrm{C}}_{2}$ and $\left.-\underline{\mathrm{C}}_{2}-\mathrm{NH}-\right), 3.33\left(\mathrm{~s}, 9 \mathrm{H},-\mathrm{O}-\mathrm{C}_{3}\right) 3.41-3.66(\mathrm{~m}, 30 \mathrm{H}$, oxyethylene), 4.14-4.22 (m, $6 \mathrm{H}$, $\mathrm{CH}_{2}-\mathrm{O}(\mathrm{CO})$ ), 4.82-4.86 (t, 3H, chiral proton of amino acid), 7.09-7.23 (m, 15H, aromatic proton of phenyl alanine), $8.04(\mathrm{~s}, 6 \mathrm{H}$, amide), $8.49(\mathrm{~s}, 3 \mathrm{H}$, aromatic proton of trimesic acid). MS (ESI): Mass: calcd for $\mathrm{C}_{75} \mathrm{H}_{108} \mathrm{~N}_{6} \mathrm{O}_{21}$ : 1428.7724; found: 1451.7679 [M $\left.\mathrm{M}^{+}+23\right]$.

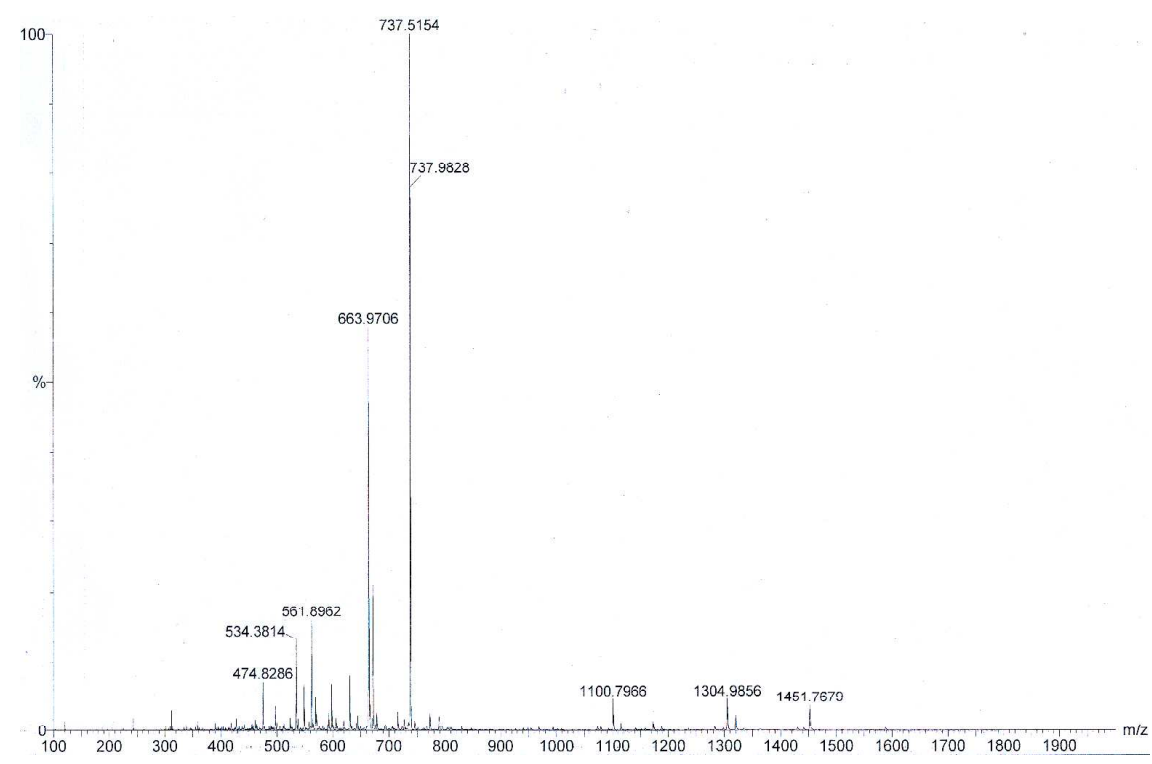

Figure S2. Mass spectra of TMA-1. 


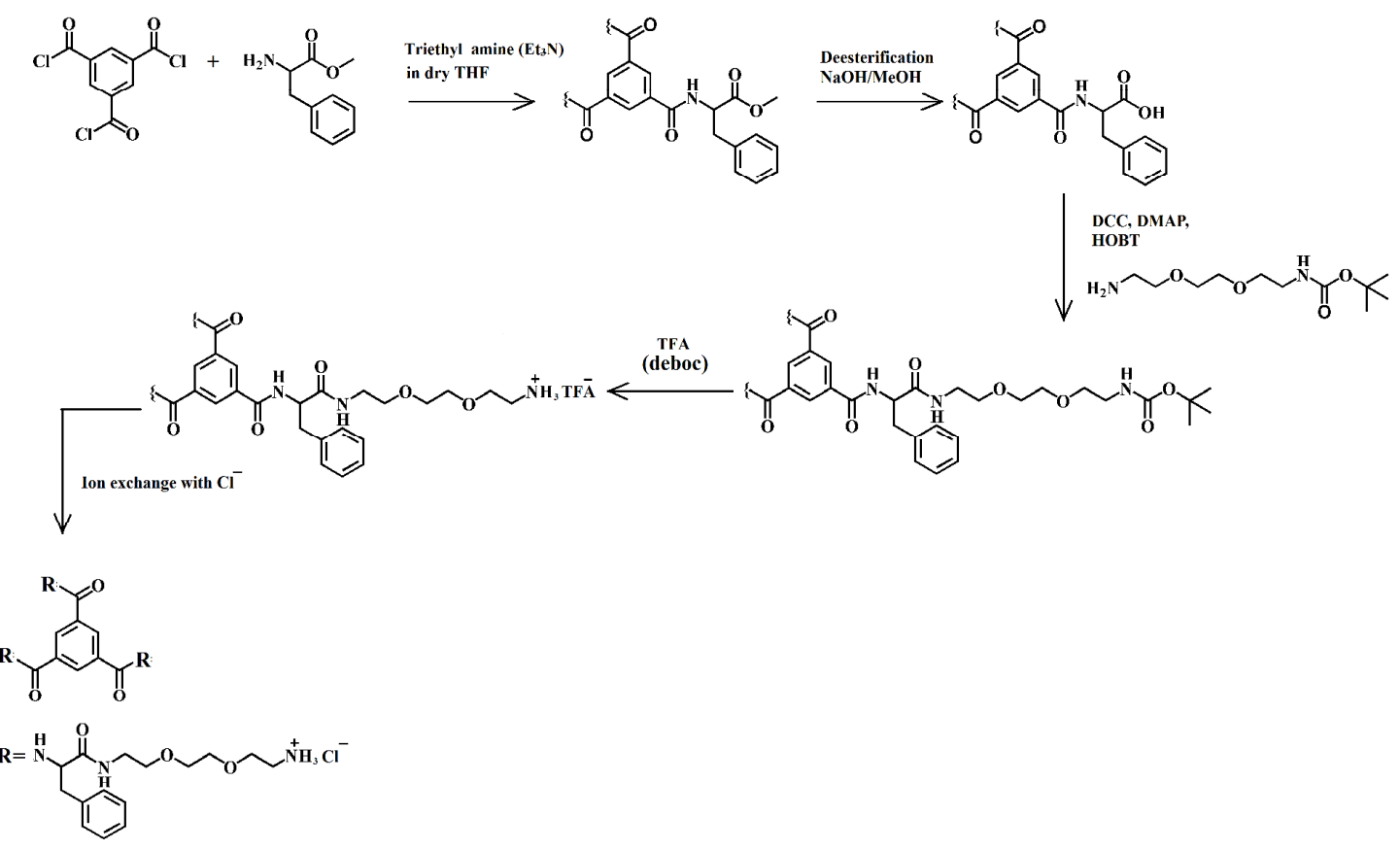

Scheme S2. Synthetic scheme for TMA-2. 


\section{Characterization of TMA-2.}

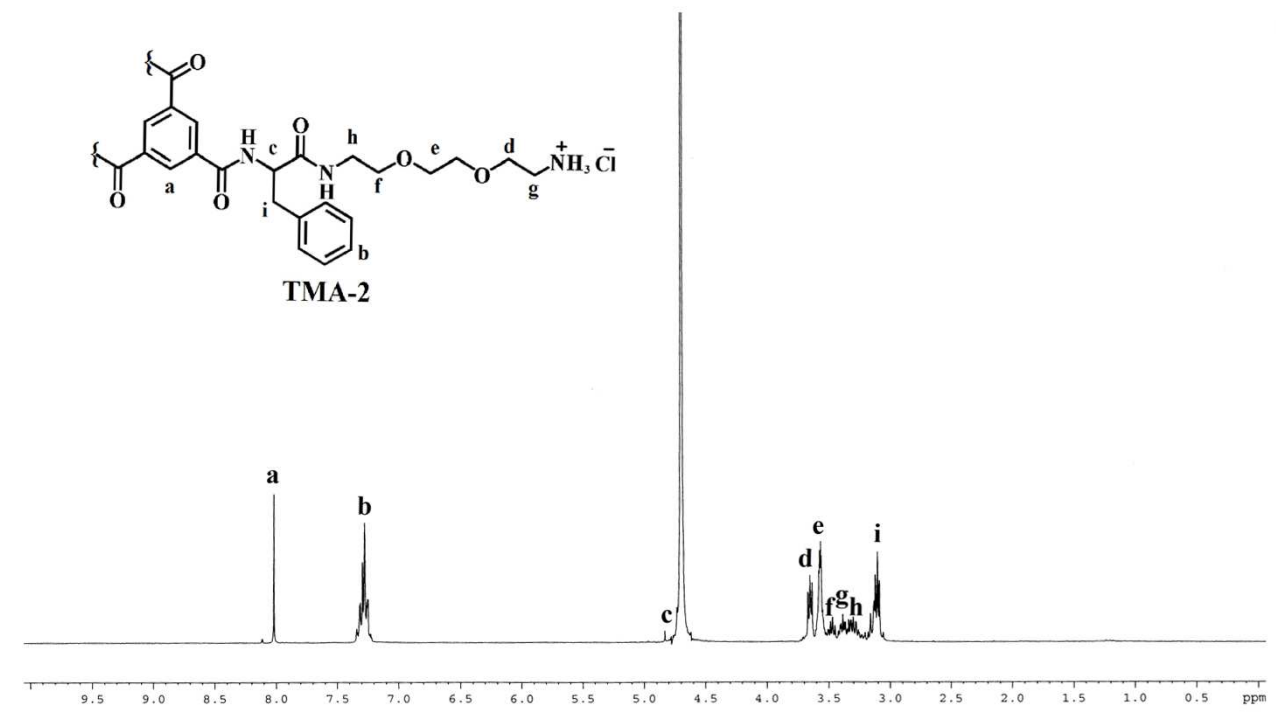

Figure S3. ${ }^{1} \mathrm{H}$ NMR spectra of TMA-2.

${ }^{1} \mathrm{H} N M R$ of TMA-2 (500 MHz, $\left.\mathrm{D}_{2} \mathrm{O}, 25^{\circ} \mathrm{C}\right) . \delta=3.06-3.18\left(\mathrm{~m}, 6 \mathrm{H}, \mathrm{Ph}-\underline{\mathrm{C}}_{2}\right), 3.21-3.28(\mathrm{~m}$, $6 \mathrm{H}, \underline{\mathrm{C}}_{2} \mathrm{NH}-\mathrm{CO}$ ), 3.30-3.39 (t, $\left.6 \mathrm{H}, \mathrm{C}_{2}-\mathrm{NH}_{3}{ }^{+}\right) 3.40-3.48,3.50-3.58$ and $3.63-3.72(\mathrm{~m}, 24 \mathrm{H}$, three different position of oxyethylene moiety), $4.80(\mathrm{~m}, 3 \mathrm{H}$, chiral proton of amino acid, peak is not clearly visible due to interference of solvent peak), 7.22-7.34 (m, 15H aromatic proton of phenyl alanine and $6 \mathrm{H}$, amide), $8.11(\mathrm{~s}, 3 \mathrm{H}$, aromatic proton of trimesic acid). Mass calcd for $\mathrm{C}_{54} \mathrm{H}_{78} \mathrm{~N}_{9} \mathrm{O}_{12}$ : 1041.5518; found:1041.5448 and 1064.3754 [ $\left.\mathrm{M}^{+}+23\right]$.

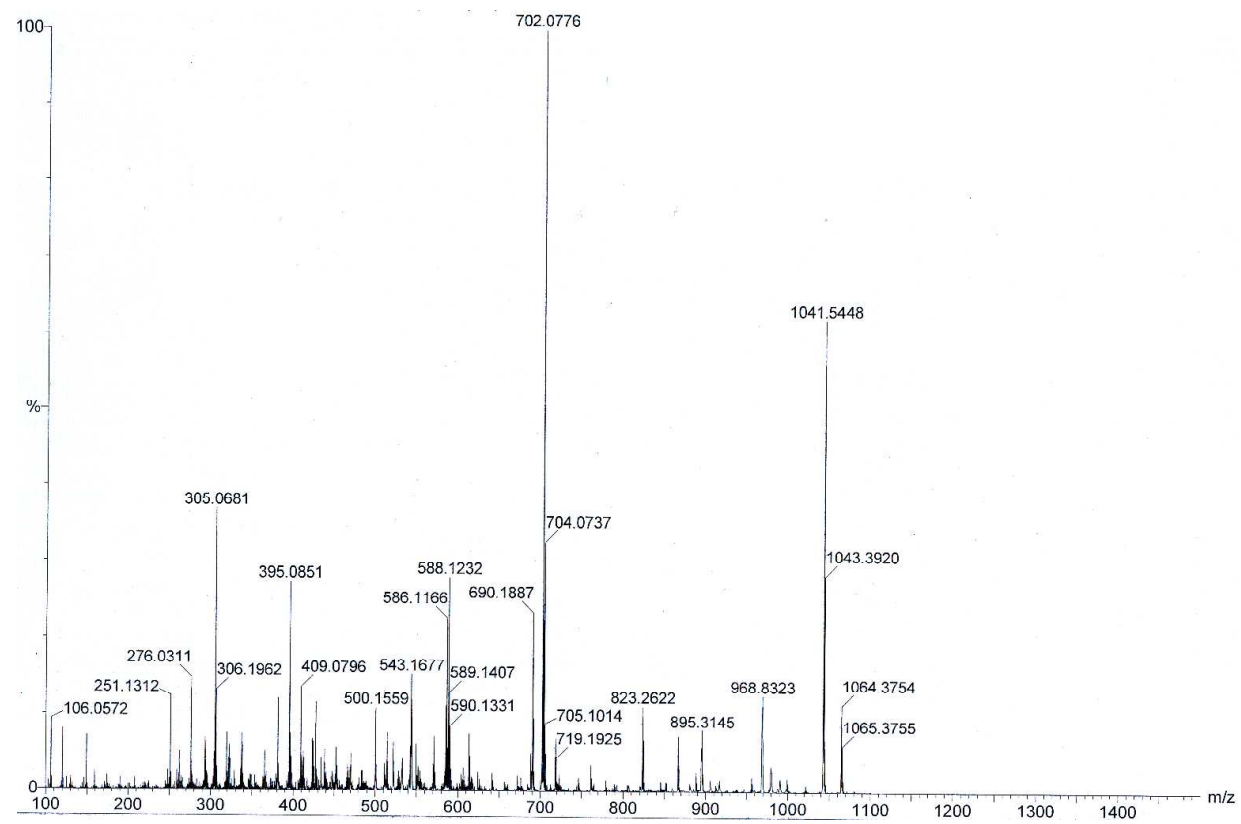

Figure S4. Mass spectra of TMA-2. 

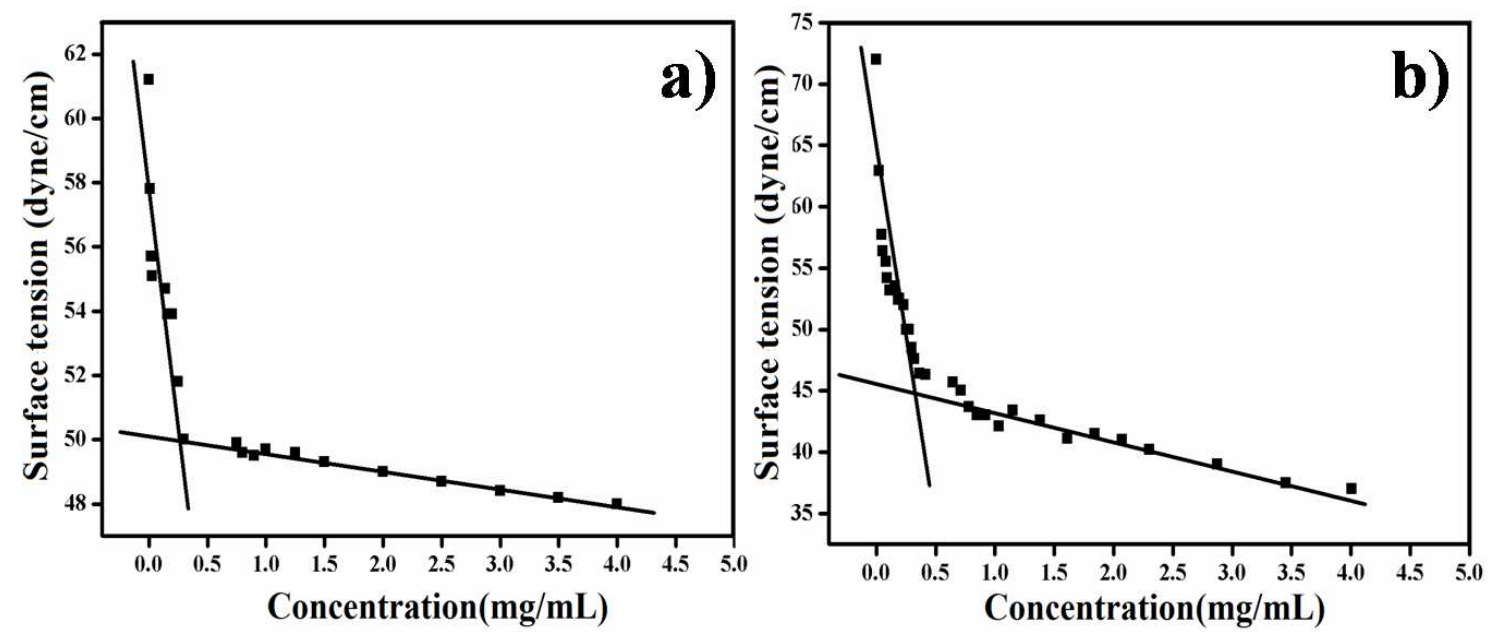

Figure S5. Plot of surface tension versus concentration of a) TMA-1 and b) TMA-2 at $25{ }^{\circ} \mathrm{C}$. 

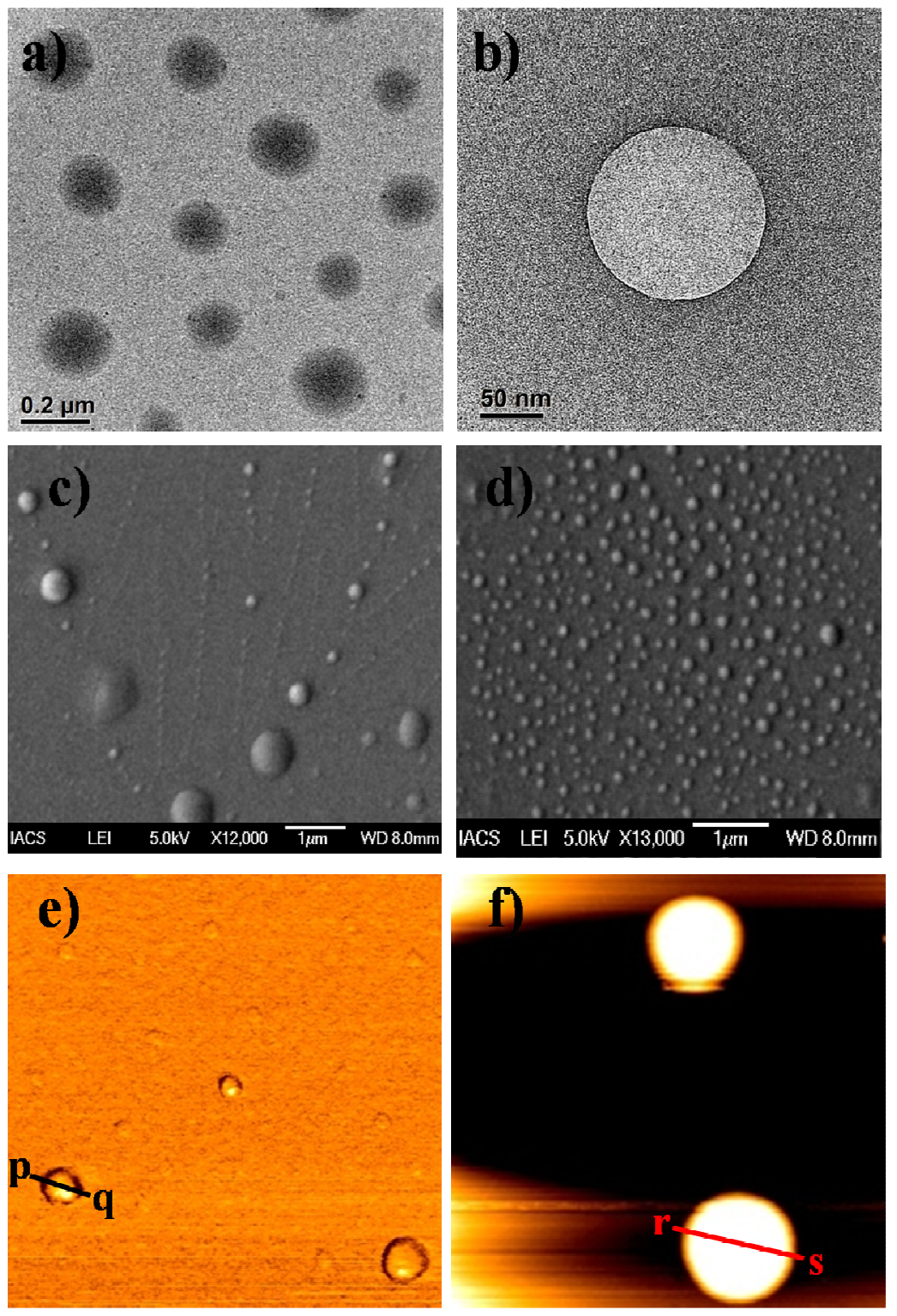

Figure S6. Negatively stained HRTEM images of a) TMA-1 vesicles prepared in DMSOwater $(2: 1, \mathrm{v} / \mathrm{v})$ b) TMA-2 vesicles prepared in water and FESEM images of c) TMA-1 vesicles prepared in DMSO-water $(2: 1, \mathrm{v} / \mathrm{v}) \mathrm{d})$ TMA-2 vesicles prepared in water, AFM images of e) TMA-1 vesicles prepared in DMSO-water $(2: 1, \mathrm{v} / \mathrm{v})(\mathrm{p}-\mathrm{q}=303 \mathrm{~nm})$ and $\mathrm{f})$ TMA-2 vesicles prepared in water $(\mathrm{r}-\mathrm{s}=121 \mathrm{~nm})$. 


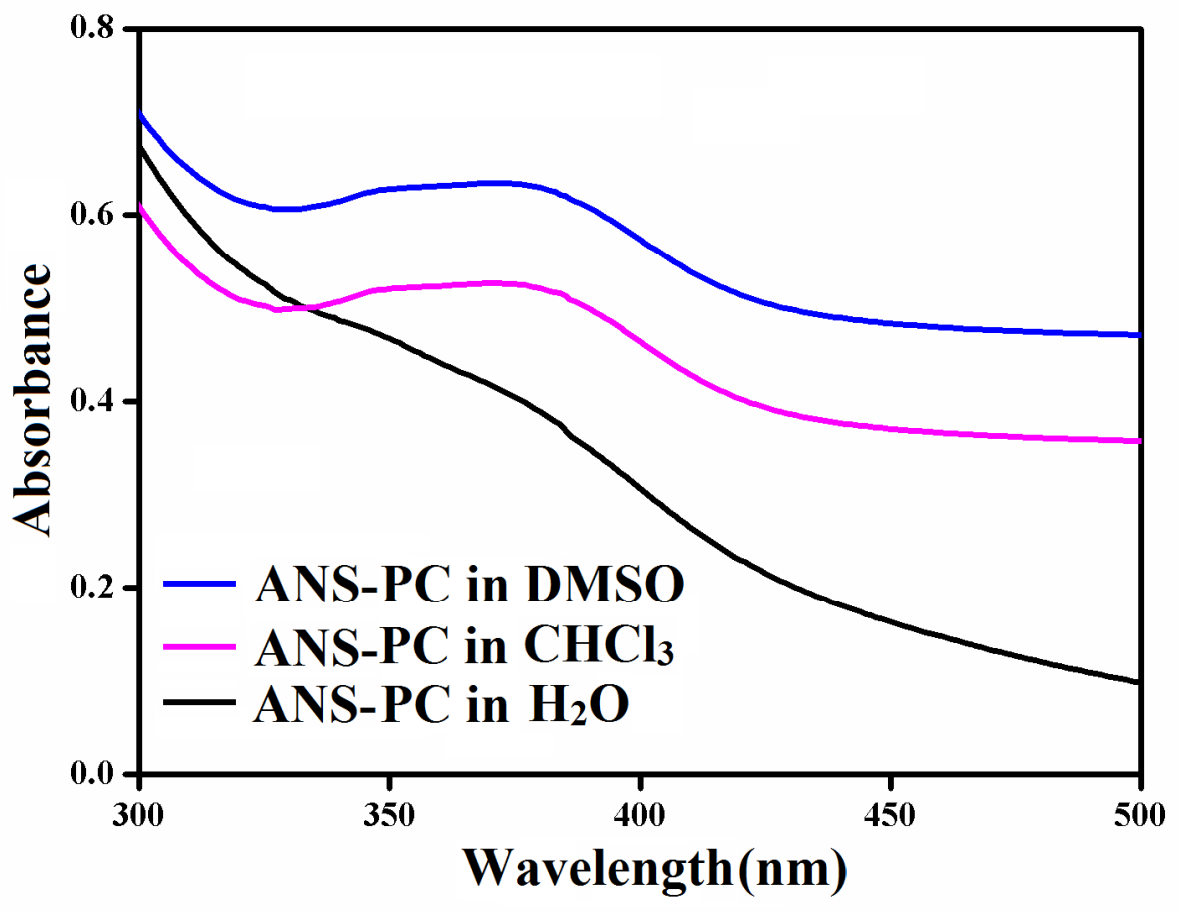

Figure S7. UV-vis spectra of ANS tagged PC in different solvents. 
a)
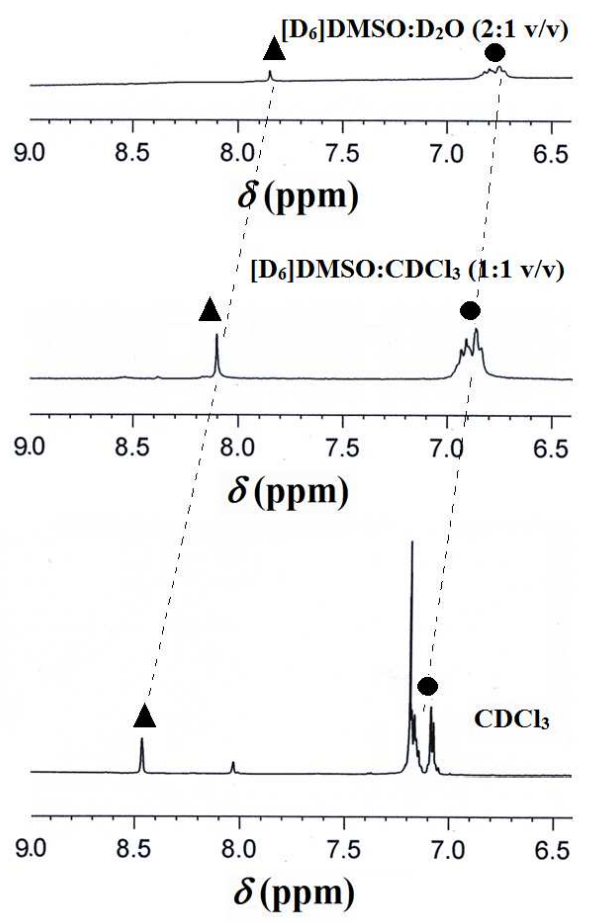

b)
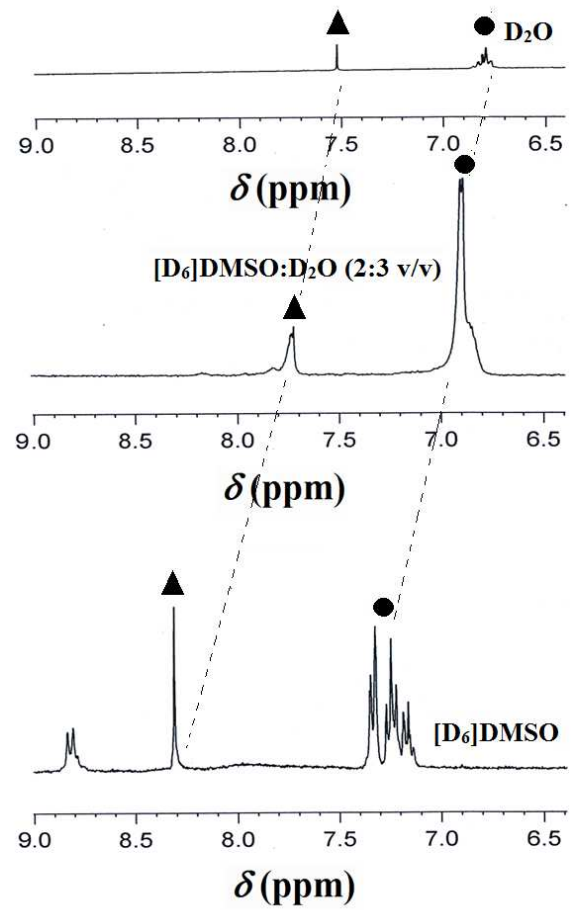

Figure S8. Solvent dependent ${ }^{1}$ H-NMR spectra of a) TMA-1 and b) TMA-2 showing the shift of aromatic protons of trimesic acid $(\boldsymbol{\Delta})$ and L-phenylalanine moiety $(\bullet)$. 

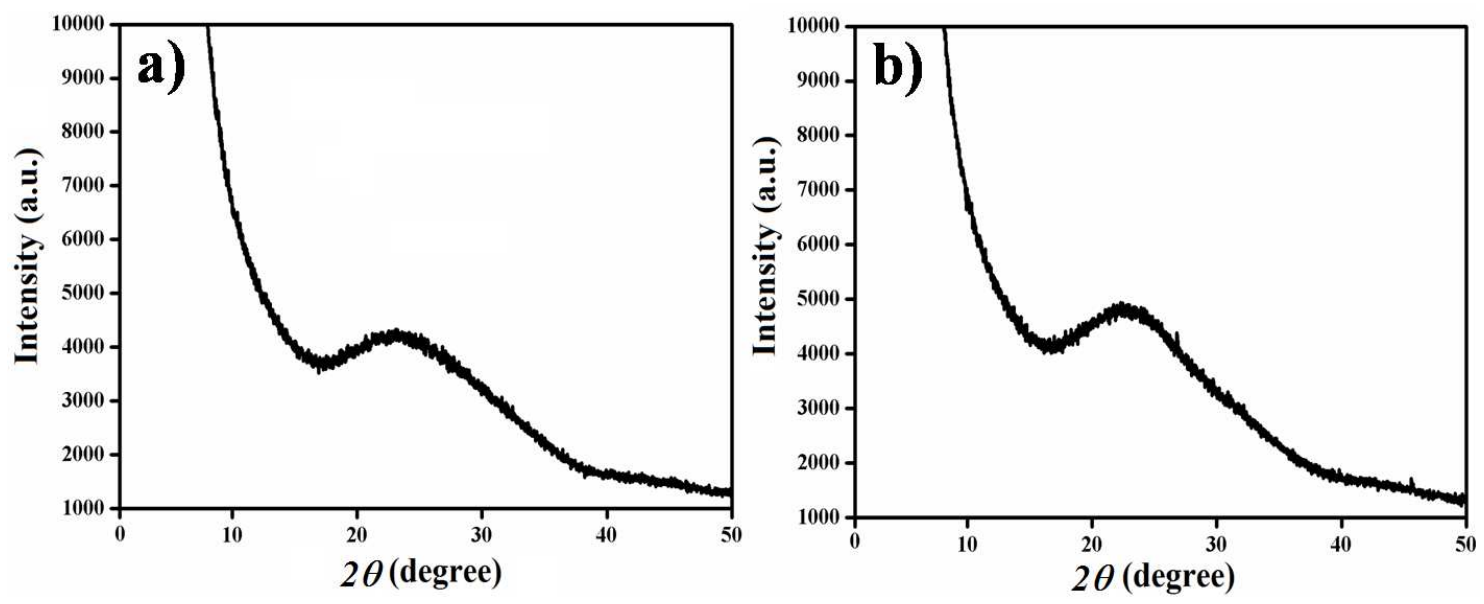

Figure S9. XRD of a) TMA-1 and b) TMA-2 vesicles. 


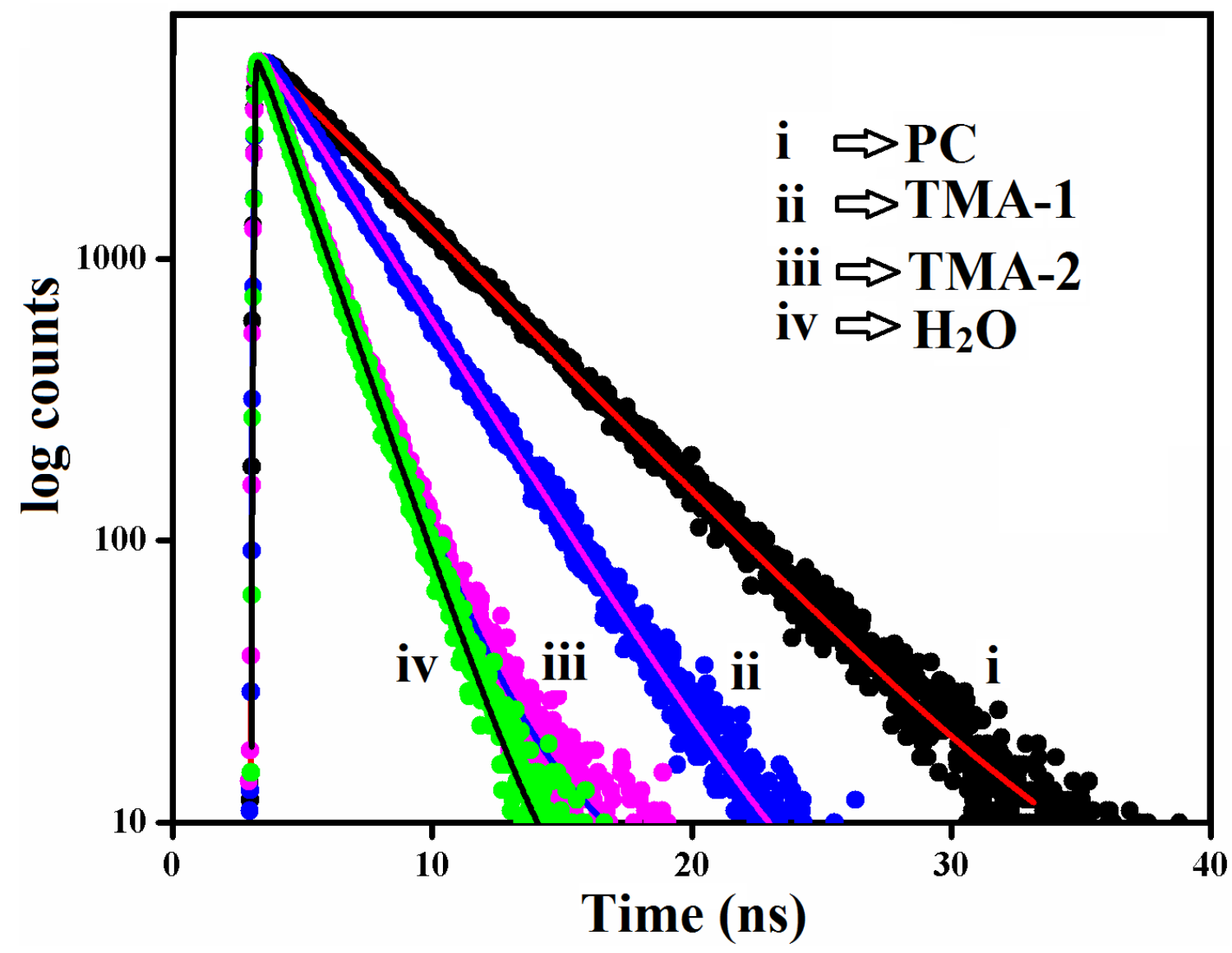

Figure S10. Decay curves of $\mathrm{C} 153$ dye encapsulated in i) PC liposomes ii) TMA-1 vesicle prepared in DMSO-water $(2: 1, \mathrm{v} / \mathrm{v})$ iii) TMA-2 vesicle prepared in water and iv) free C153 in water (excitation wavelength at $405 \mathrm{~nm}$.) 


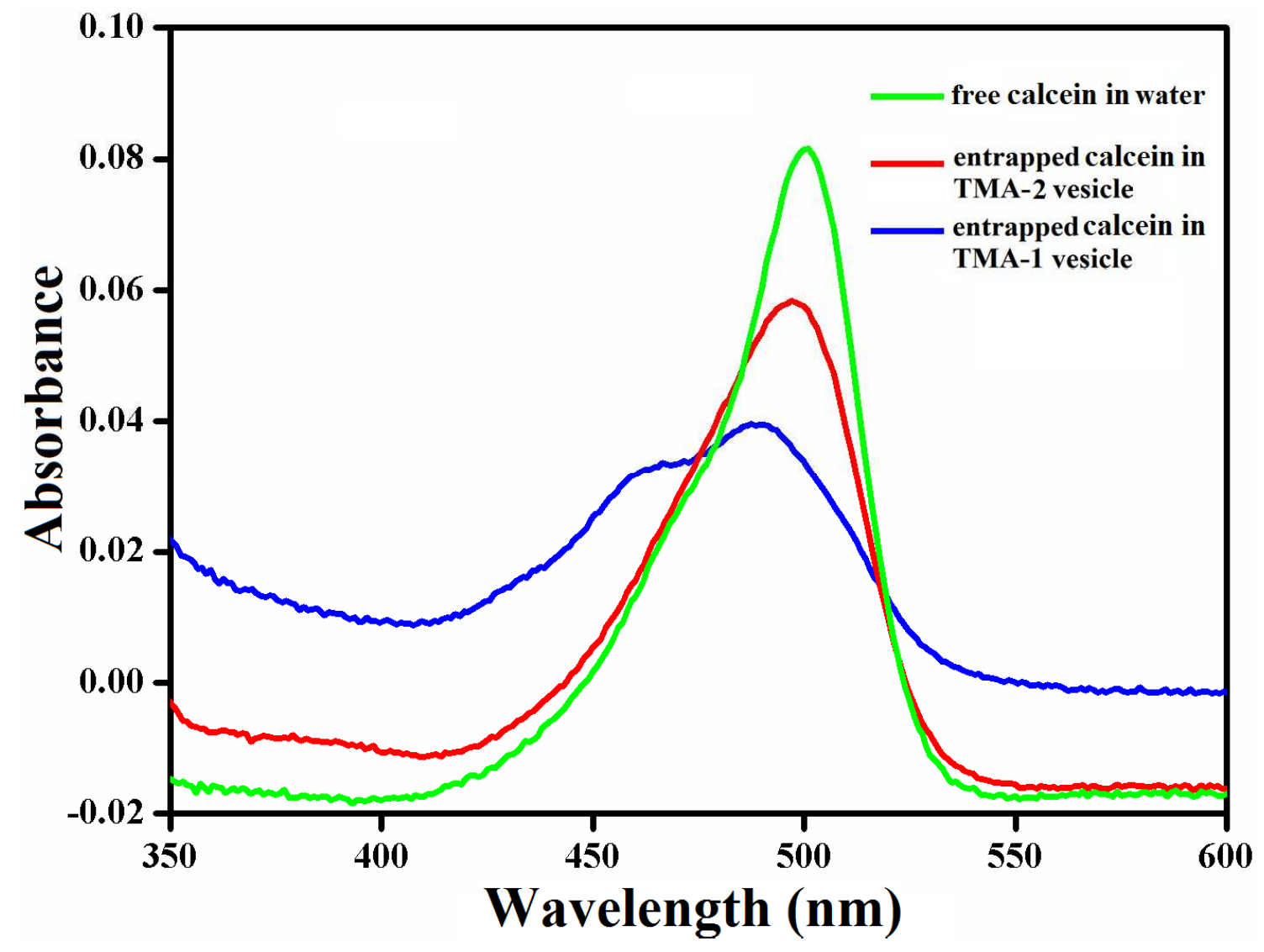

Figure S11. UV-vis absorbance spectra of calcein entrapped TMA-1 in DMSO-water (2:1, $\mathrm{v} / \mathrm{v}$ ) and TMA-2 in water vesicles and free calcein in water. 

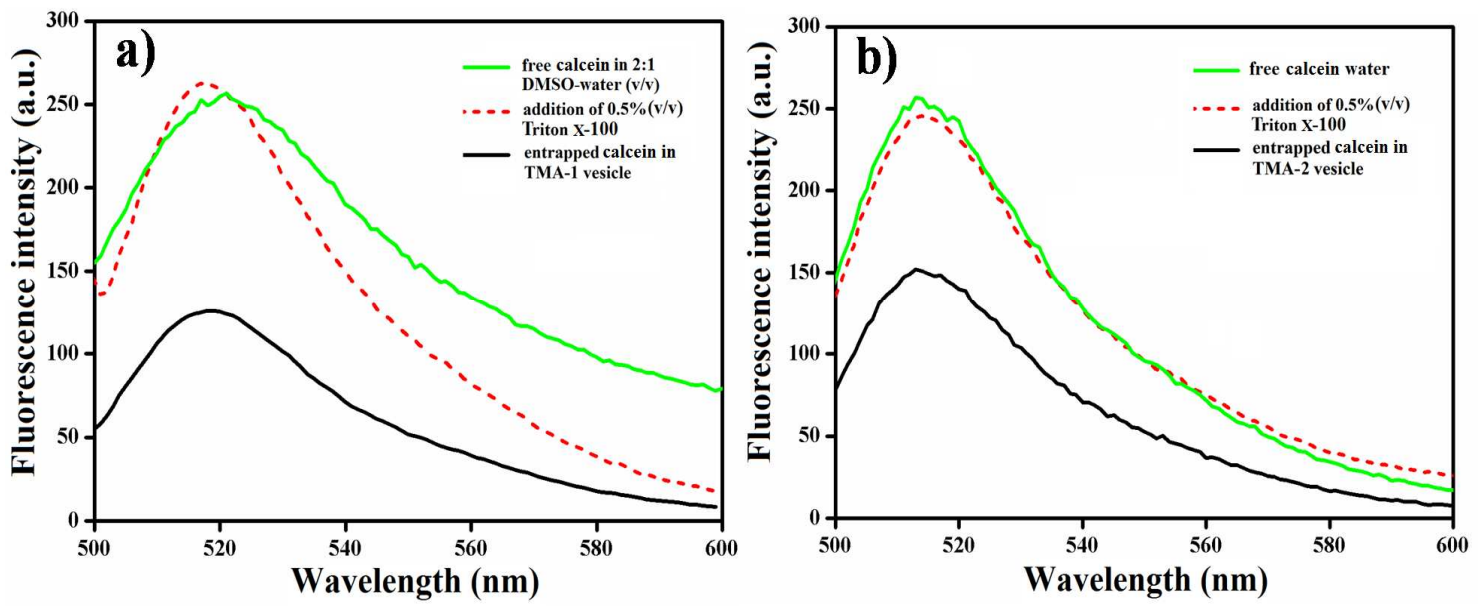

Figure S12. Emission spectra of calcein entrapped within a) TMA-1 vesicle and b) TMA-2 vesicles, after treating with Triton X-100 and free calcein. 


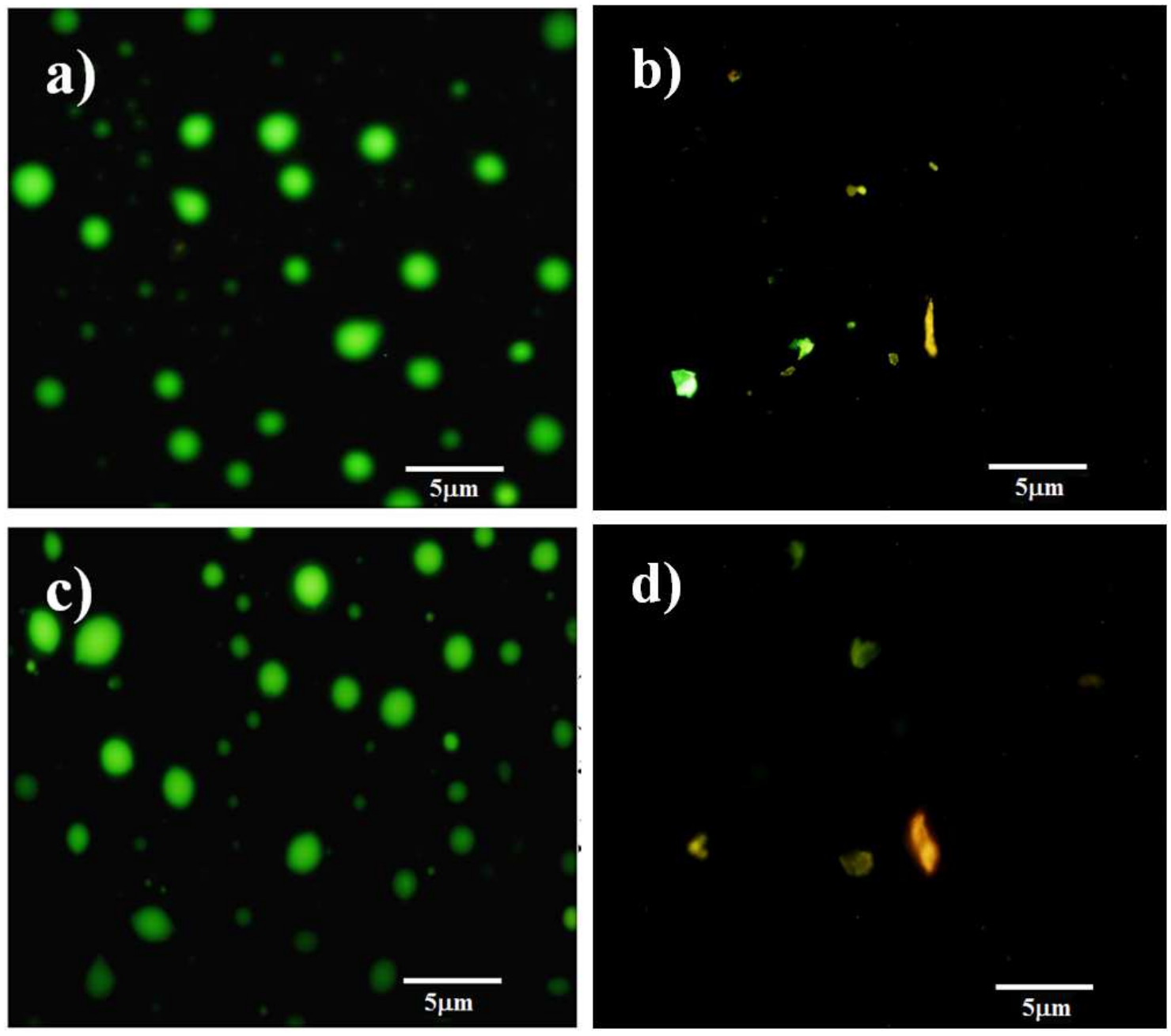

Figure S13. Fluorescence microscopic images $\left(\lambda_{\mathrm{ex}}=450 \mathrm{~nm}\right)$ of a) calcein encapsulated TMA-1 vesicles and b) after treating with Triton X-100 on TMA-1 vesicle; c) calcein encapsulated TMA-2 vesicles and d) after treating with Triton X-100 on TMA-2 vesicle. 

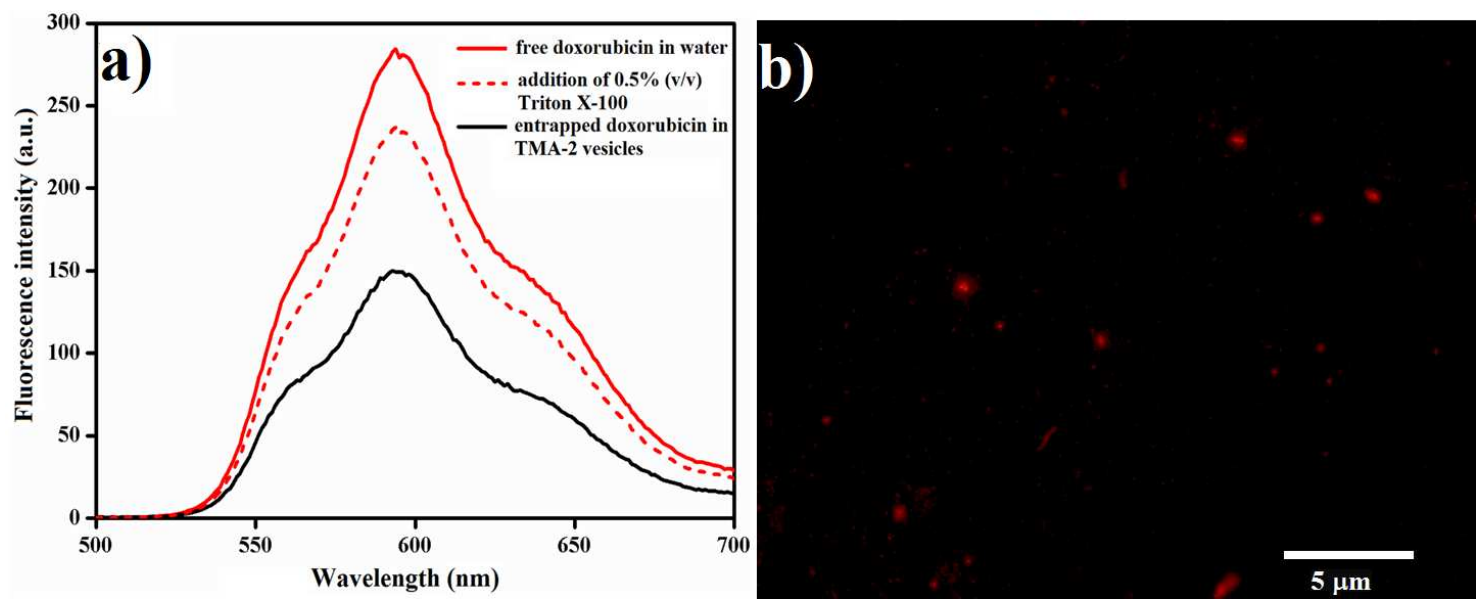

Figure S14. a) Emission spectra of doxorubicin entrapped within TMA-2 vesicles, after treating with Triton X-100 and free doxorubicin. b) Fluorescence microscopic images $\left(\lambda_{\mathrm{ex}}=\right.$ $590 \mathrm{~nm}$ ) of doxorubicin encapsulated TMA-2 vesicles after treating with Triton X-100. 


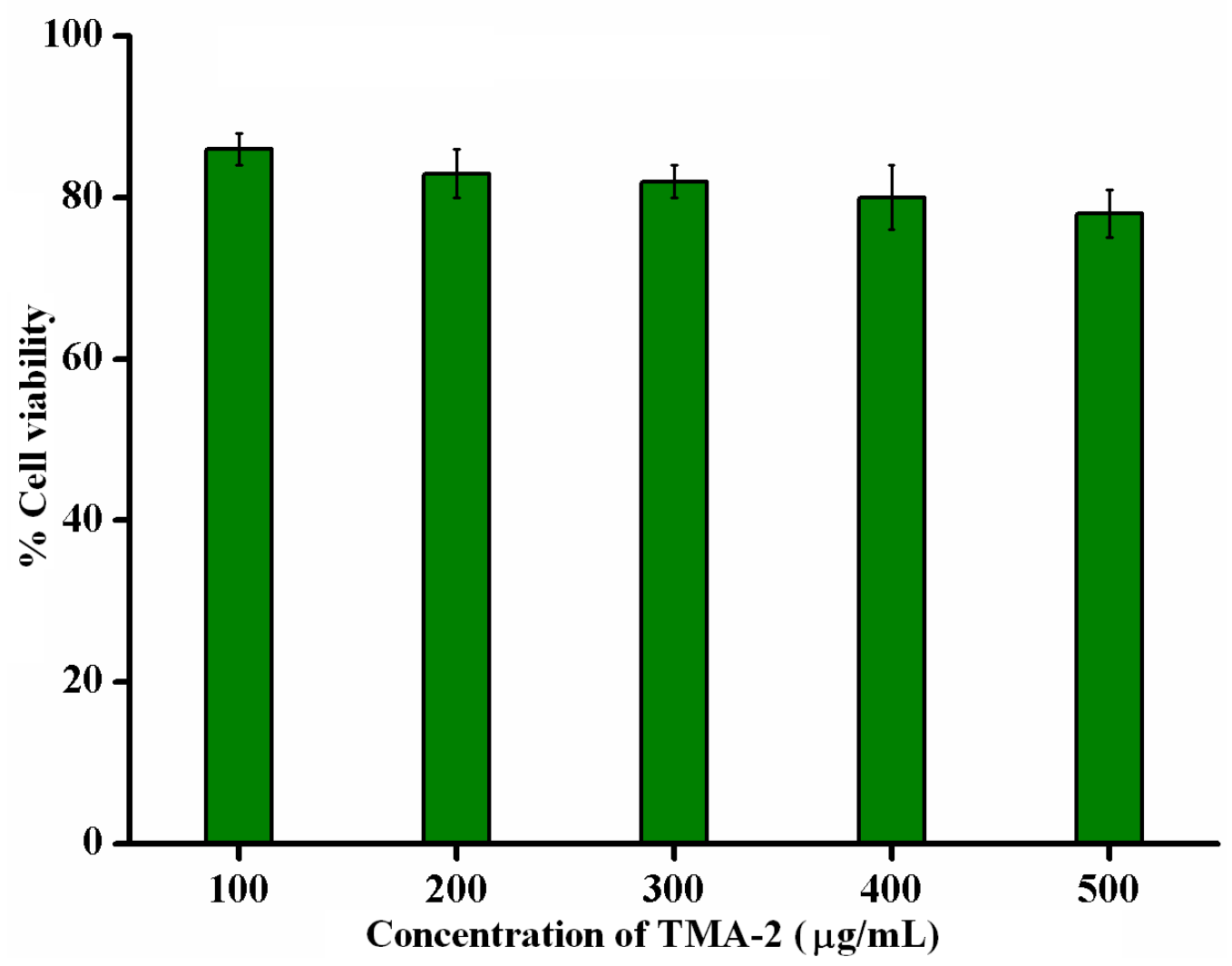

Figure S15. Cell viability of TMA-2 vesicles with B16F10 cells upon $12 \mathrm{~h}$ of incubation, the error bars represent $(\mathrm{SD}, \mathrm{n}=5)$. 